\title{
NDRG2 mRNA levels and miR-28-5p and miR-650 activity in chronic lymphocytic leukemia
}

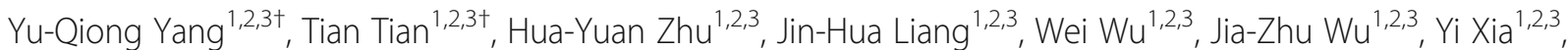
Li Wang ${ }^{1,2,3}$, Lei Fan ${ }^{1,2,3}$, Jian-Yong $\mathrm{Li}^{1,2,3}$ and Wei $X u^{1,2,3^{*}}$ (D)

\begin{abstract}
Background: NDRG2 is identified as a tumor suppressor gene in many tumors, and functions in cell proliferation, differentiation and apoptosis. Recent data indicate that NDRG2 expression is up-regulated by TP53. Moreover, proposed mechanisms of NDRG2 inactivation include epigenetic silencing of the NDRG2 promoter and downregulation by microRNAs (miRNAs). However, few studies have ever been done on the role of NDRG2 and the NDRG2-regulating miRNAs interference in chronic lymphocytic leukemia (CLL).
\end{abstract}

Methods: NDRG2 and microRNAs mRNA levels in CLL subjects were assessed by quantitative real-time polymerase chain reaction (qRT-PCR). The dual-luciferase reporter assay was performed to determine NDRG2-related miRNAs. Low expression of mature exogenous miRNAs in CLL cells was established by transient transfection. NDRG2 protein levels in CLL cells were detected by western blot. In addition, flow cytometry was conducted to examine the apoptosis of CLL cells.

Results: Lower expression of NDRG2 was found in the B-cells from 102 CLL patients compared the 40 normal subjects $(P<0.001)$. Patients with advanced Binet stage $(P=0.001)$, high lactate dehydrogenase $(L D H)$ level $(P=0.036)$, un-mutated immunoglobulin heavy chain variable region gene (IGHV) $(P=0.004)$ and those with p53 aberrations $(P<0.001)$ had a markedly lower levels of NDRG2 mRNA. This decrease was associated with briefer time-to-treatment $(P=0.001)$ and poorer survival $(P<0.001)$. High expression of miR-28-5p and miR-650 was associated with Binet $\mathrm{B} / \mathrm{C}$ stage $(P=0.044)$ and IGHV un-mutated $(P=0.011)$, as well as Binet $\mathrm{B} / \mathrm{C}$ stage $(P=0.013)$ and p53 aberrations $(P=0.037)$, respectively. Inhibition of miR-28-5p or miR-650 could induce more apoptosis in CLL cells with germline TP53.

Conclusions: NDRG2 mRNA levels might be a useful prognostic variable for patients of CLL and up-regulating NDRG2 transcription may be a therapy approach in CLL without p53 aberrations.

Keywords: Chronic lymphocytic leukemia, NDRG2, miR-28-5p, miR-650

\footnotetext{
* Correspondence: xuwei10000@hotmail.com

†Yu-Qiong Yang and Tian Tian contributed equally to this work.

'Department of Hematology, the First Affiliated Hospital of Nanjing Medical

University, Province Hospital, Nanjing 210029, Jiangsu, China

${ }^{2}$ Key Laboratory of Hematology of Nanjing Medical University, Nanjing

210029, China

Full list of author information is available at the end of the article
}

(c) The Author(s). 2018 Open Access This article is distributed under the terms of the Creative Commons Attribution 4.0 International License (http://creativecommons.org/licenses/by/4.0/), which permits unrestricted use, distribution, and reproduction in any medium, provided you give appropriate credit to the original author(s) and the source, provide a link to the Creative Commons license, and indicate if changes were made. The Creative Commons Public Domain Dedication waiver (http://creativecommons.org/publicdomain/zero/1.0/) applies to the data made available in this article, unless otherwise stated. 


\section{Background}

NMYC downstream-regulated gene-2 (NDRG2) serves as a tumor suppressor gene, and play essential parts in cell proliferation, differentiation and apoptosis. Associations between NDRG2 expression and cancer biology were described in brain, liver, lung, thyroid and breast cancers as well as in hematologic neoplasms [1-6]. Recent data indicate that NDRG2 expression, up-regulated by TP53 [7], can inhibit STAT3 activation and NF-kB activity [8, 9]. Proposed mechanisms of NDRG2 inactivation include epigenetic silencing of the NDRG2 promoter and downregulation by microRNAs (miRNAs) $[1,10]$. However, few data are available on the role of NDRG2 in chronic lymphocytic leukemia (CLL).

\section{Methods}

\section{Subjects}

Consecutive 102 CLL patients untreated were enrolled between January 2004 and December 2013. All subjects were given written informed consent complying the requirements of the Declaration of Helsinki. The research was approved by the Institutional Review Boards of Nanjing Medical University. CLL diagnosis was based on the criteria specified in the National Cancer Institution [11]. Variables ascertained in diagnosis included age, gender, Binet staging, blood absolute lymphocyte count (ALC), lactate dehydrogenase (LDH), $\beta_{2}$-microglobulin $\left(\beta_{2}-\mathrm{MG}\right), \mathrm{CD} 38, \mathrm{ZAP}-70$, mutation status of IGHV gene, TP53 mutation (exon 4-9) status, and cytogenetics (studied by fluorescence in situ hybridization; FISH). In addition, 40 age-matched healthy controls (HC) were recruited between January 2012 and December 2013 from the center of Health Examination.

\section{Primary cell cultures}

CLL cells from 11 subjects were isolated from venous blood by density-gradient centrifugation. $>90 \%$ of cells were B-cells, as determined by staining for $\mathrm{CD} 5^{+} \mathrm{CD} 19^{+}$ coexpression (Becton Dickinson, USA), were cultured in RPMI-1640 media. Ten percent fetal calf serum (Gibco, USA) was added to the media. CLL cells were cultured at $37{ }^{\circ} \mathrm{C}$ with $5 \% \mathrm{CO}_{2}$ in humidified atmosphere.

\section{NDRG2 mRNA detection}

Whole RNAs was extracted using Trizol reagent (Invitrogen). RNA was reversely transcribed using random hexamers, and amplified with fluorescent dye SYBR Green MasterMix and qRT-PCR specific reverse primers (Additional file 1). $\beta$-actin was used as an internal control. Reaction conditions for NDRG2 and $\beta$-actin were one cycle at $95{ }^{\circ} \mathrm{C}$ for $5 \mathrm{~min}$ followed by 35 cycles at $95{ }^{\circ} \mathrm{C}$ for $30 \mathrm{~s}, 60{ }^{\circ} \mathrm{C}$ for $30 \mathrm{~s}$ and $72{ }^{\circ} \mathrm{C}$ for 30 s. A final extention was run at $72{ }^{\circ} \mathrm{C}$ for $5 \mathrm{~min}$. Relative expression was analyzed using the comparative cycle threshold $(\mathrm{Ct})$ method. $\Delta \mathrm{Ct}$ was calculated by subtracting the $\mathrm{Ct}$ of $\beta$-actin from those for the gene of interest. Relative amounts of the interest gene were calculated using eq. $2^{-\Delta}$ Ct . Reactions for qRT-PCR were performed in triplicate, using the Applied Biosystems ABI 7500 Real-time PCR system (Applied Biosystems, USA). Sequences of amplifed production were confirmed via DNA sequencing.

\section{Dual luciferase reporter assay}

NDRG2-related miRNAs were initially identified in bioinformatics miRNA databases such as target scan (http:/ www.targetscan.org/) and miR-Base (http://www.mirbase.org/). Dual luciferase reporter assay (Promega, USA) was used to evaluate whether the conserved miRNAs with higher scores binds directly to NDRG2. Renilla-luciferase assay was performed with a modified expression pEZX vector containing the complete $3^{\prime}$ untranslated regions (UTR) region of NDRG2 cloned in the 3'UTR region of dual luciferase gene. The miRNAs or negative controls (NC) were transfected in the HEK293T cell line together with pEZX vector using lipofectamine 2000 for dual-luciferase assay. HEK293T cell line was obtained from ATCC (American Type Culture Collection, Manassas, VA, USA, ATCC@-ACS 4500) in 2012. The cell line has been authenticated by using Single Tandem Repeat (STR) profiling method and there is no mycoplasma contamination. All cells were transfected for $24 \mathrm{~h}$ and assayed using a Luciferase Assay Kit (Promega, USA).

\section{Transient transfection}

CLL cells were transferred in 6-well plates by density of $5.0 \times 10^{6}$ cells/well and transiently transfected with $100 \mathrm{nM}$ of mature miRNA inhibitors of miR-28-5p and miR-650 and $100 \mathrm{nM}$ as random negative-control miRNA (miR-NC) (GenePharma Company, China) using Lipofectamine 2000 Transfection Reagent (Invitrogen, USA) according to the manufacturer's protocol.

\section{Western blotting}

Cells were harvested with lysis buffer $24 \mathrm{~h}$ after transfection with miRNA inhibitors (including miR-28-5p, miR-650 and negative control miRNA inhibitors). Protein concentration was calculated using BCA (Beyotime, China). Total protein was separated using $10 \%$ sodium dodecyl sulfate-polyacrylamide gel, transferred to PVDF membranes and incubated with goat monoclonal antibody against NDRG2 (Santa Cruz Biotechnology, USA) in 1:200 dilutions. The secondary antibody was rabbit anti-goat IgG (Santa Cruz Biotechnology, USA) in 1:2500 dilutions. The normalized control used was GAPDH. 


\section{Apoptosis assay}

The apoptotic ratio of CLL cells was detected using Annexin V/propidium iodide (PI) flow cytometric assay (Becton, Dickinson and Company). CLL cells after 24 h-transfection were washed twice with cold phosphate-buffered saline (PBS), and then re-suspended in $500 \mu \mathrm{L}$ binding buffer (Bestbio, Shanghai, China). Annexin V and PI were added to the transferred cells and the plate was incubated in the dark for $15 \mathrm{~min}$ at room temperature. Apoptosis cells analysis was performed using a FACSCalibur flow cytometer and CellQuest software (BD Biosciences, USA).

\section{Statistical analyses}

Statistical analyses were performed using SPSS software for Windows (version 20.0). The difference of target gene mRNA expression between groups with different prognostic factors was described using the Mann-Whitney $\mathrm{U}$ test. The difference of miRNA and NDRG2 expression and apoptosis rate between groups was calculated using the Paired-Samples t- Test. Survival was calculated as time from diagnosis until death or loss to follow-up or to May 2017. Time to first treatment (TTT) was calculated as interval from diagnosis until first CLL-specific treatment or the last follow-up. Survival and TTT were estimated by the Kaplan-Meier method and results were compared using the log-rank test. Prognostic influence of variables was tested using the Cox proportional hazards model in univariate and multivariate analyses. Protein bands of Western blot were quantified through the Image J program for Windows after normalizing the data for GAPDH. 2-sided $P$-values $<0.05$ were considered statistically significant.

\section{Results}

\section{Clinical variables}

Baseline variables for subjects are shown in Table 1 . Median age at diagnosis was 59 years (range, 1686 years). Sixty-nine were males. Thirty-eight subjects (37.2\%) were in Binet A, 33 (32.4\%) in Binet B and 31 (30.4\%) in Binet C. p53 aberrations including TP53 mutation or p53 deletion was detected in 24 patients (23.5\%). Median duration of follow-up is 71 months (range, 14-160 months). Sixty-five received chemotherapy or chemoimmunotherapy, and the rest patients were untreated complying with the international workshop on chronic lymphocytic leukemia (IWCLL) criteria. Twenty-five subjects died of CLL-related causes.

\section{NDRG2 expression and association with other variables}

Relative expression level of NDRG2 mRNA in subjects versus normal controls was 0 to 0.0467 (median: 0.0017) and from 0.0028 to 0.0343 (median: 0.0044). Down-expression
Table 1 Clinical and biological variables of 102 subjects with chronic lymphocytic leukemia

\begin{tabular}{|c|c|}
\hline Characteristic & Value (\%) \\
\hline \multicolumn{2}{|l|}{ Age } \\
\hline$\leq 60$ years & $58(56.9)$ \\
\hline$>60$ years & $44(43.1)$ \\
\hline \multicolumn{2}{|l|}{ Sex } \\
\hline Male & $69(67.6)$ \\
\hline Female & $33(32.4)$ \\
\hline \multicolumn{2}{|l|}{ Binet stage } \\
\hline A & $38(37.2)$ \\
\hline B & $33(32.4)$ \\
\hline C & $31(30.4)$ \\
\hline \multicolumn{2}{|l|}{ Lymphocytes } \\
\hline$<50 \times 10^{9} / \mathrm{L}$ & $71(69.6)$ \\
\hline$\geq 50 \times 10^{9} / \mathrm{L}$ & $31(30.4)$ \\
\hline \multicolumn{2}{|l|}{ LDH } \\
\hline$\leq \cup L N$ & $79(77.5)$ \\
\hline$>$ ULN & $20(22.5)$ \\
\hline \multicolumn{2}{|l|}{$\beta_{2}-M G$} \\
\hline$\leq \cup L N$ & $34(33.3)$ \\
\hline$>$ ULN & $68(66.7)$ \\
\hline \multicolumn{2}{|l|}{$\operatorname{CD} 38(n=100)$} \\
\hline$<30 \%$ & $75(75.0)$ \\
\hline$\geq 30 \%$ & $25(25.0)$ \\
\hline \multicolumn{2}{|l|}{ ZAP-70 $(n=100)$} \\
\hline$<20 \%$ & $55(55.0)$ \\
\hline$\geq 20 \%$ & $45(45.0)$ \\
\hline \multicolumn{2}{|l|}{ IGHV $(n=101)$} \\
\hline Mutated & $61(60.4)$ \\
\hline Unmutated & $40(39.6)$ \\
\hline \multicolumn{2}{|l|}{ p53 aberrations } \\
\hline No TP53 mutation or p53 deletion & $78(76.4)$ \\
\hline TP53 mutation or p53 deletion & $24(23.5)$ \\
\hline \multicolumn{2}{|l|}{ del (11q22.3) $(n=93)$} \\
\hline Negative & $78(83.9)$ \\
\hline Positive & $15(16.1)$ \\
\hline \multicolumn{2}{|l|}{ del $(13 q 14)(n=65)$} \\
\hline Negative & $39(60.0)$ \\
\hline Positive & $26(40.0)$ \\
\hline \multicolumn{2}{|l|}{$+12(n=81)$} \\
\hline Negative & $69(85.2)$ \\
\hline Positive & $12(14.8)$ \\
\hline
\end{tabular}


of NDRG2 was found in CLL patients compared to HC $(P<0.001$, Fig. 1a).

NDRG2 expression was analyzed in CLL patients for association with baseline variables (Table 2). Significant associations were found with Binet stage $\mathrm{B} / \mathrm{C}$ vs. A $(P=0.001)$, high $\mathrm{LDH}$ level vs. normal $\mathrm{LDH}$ level $(P=0.036), I G H V$ un-mutated vs. IGHV mutated $(P=0.004)$ and p53 aberrations vs. no p53 aberrations $(P<0.001)$ (Fig. 1b).

\section{NDRG2 expression is associated with TTT and survival}

Patients were subdivided into high- and low-NDRG2 groups by NDRG2 expression level (median split) to analyze the survival. The cohort of CLL was initially split into low $(N=51)$ and high $(\mathrm{N}=51)$ based on a value of 0.0017 . With the median follow-up of 71 months (range, 14-160 months), patients in the low NDRG2 mRNA cohort had a briefer TTT (median, 18 months, range, 1-94 months, $P=0.001$ ) (Fig. 1c) and worse survival (median, 93 months, range, $14-136$ months, $P<0.001$ ) (Fig. 1d) compared to those in high NDRG2 mRNA cohort.

Univariate analysis indicated that Binet stage $\mathrm{B} / \mathrm{C}$, un-mutated IGHV, p53 aberrations and low NDRG2 mRNA were significantly associated with a brief TTT (Table 3), whereas multivariate analysis only showed significance with Binet stage $\mathrm{B} / \mathrm{C}(P=0.008$; HR 2.48; $[1.27,4.84])$, p53 aberrations $(P=0.015$; HR 2.46; [1.19,
5.09]) and low NDRG2 mRNA $(P=0.022$; HR 2.01; $[1.11,3.64]$ ) (Table 3).

Univariate analysis for overall survival (OS) suggested that Binet stage B/C, CD38-positive, un-mutated IGHV, p53 aberrations and low NDRG2 mRNA were significantly associated with worse survival (Table 3 ). However, only un-mutated IGHV $(P=0.024$; HR 3.03; $[1.16,7.95])$, p53 aberrations $(P=0.013$; HR 3.95; $[1.34,11.67])$ and low NDRG2 mRNA $(P=0.040$; HR 3.43; $[1.06,11.14])$ remained significant by multivariate analysis.

\section{miR-28-5p and miR-650 directly targeted NDRG2}

The computational algorithms, including TargetScan and RNAhydrid, were collectively used identify potential miRNAs that target NDRG2. As is shown in Additional file 2, the bioinformatics analysis identified four miRNAs (miR-29a, miR-29c, miR-28-5p and miR-650) as possible regulators of NDRG2. Moreover, we constructed luciferase reporter assays with 3 '-untranslated regions (UTR) of NDRG2 (pEZX-NDRG23'-UTR) to further determine whether NDRG2 was directly regulated by these miRNAs. The luciferase reporter was introduced to $100 \mathrm{nM}$ of these miRNAs mimics and miR-NC into HEK293T cells. The luciferase activity was significantly reduced in the cell line when pEZX-NDRG2-3'-UTR was transfected with miR-28-5p and miR-650 mimics. Furthermore, we introduced point mutations into the corresponding complementary sites in the 3'-UTR of NDRG2 to

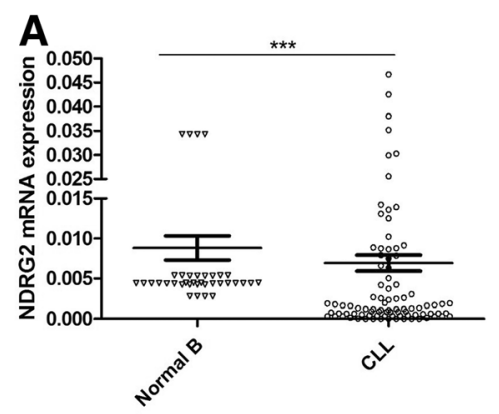

B
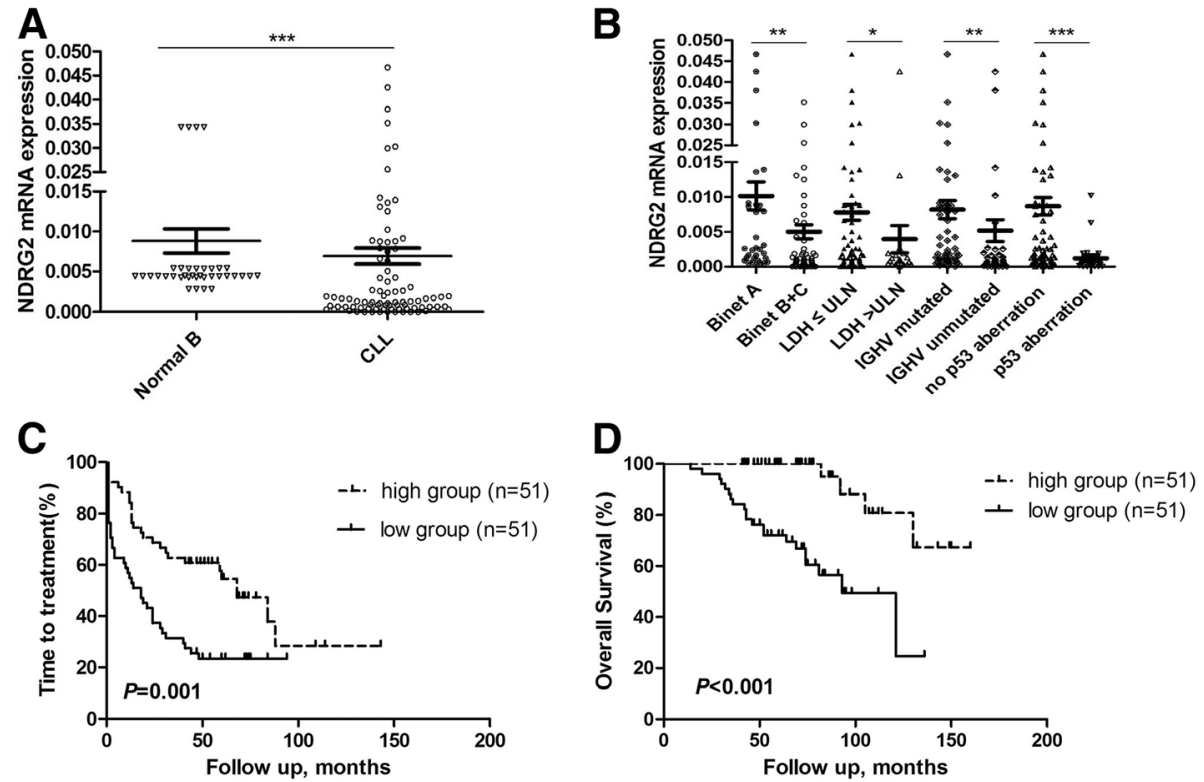

Fig. 1 a Determination of NDRG2 mRNA expression in the102 CLL patients and 40 normal B-cell samples by RT-PCR. ${ }^{* * *} P<0.001$. b Dot-plot of NDRG2 mRNA expression in CLL patients. Significant associations were found with Binet stage B/C vs. A, high LDH level vs. normal LDH level, IGHV un-mutated vs. IGHV mutated and p53 aberrations vs. no p53 aberrations. ${ }^{* *} P<0.001,{ }^{* *} P<0.01,{ }^{*} P<0.05$. c Time to treatment (TTT) curve of CLL based on NDRG2 mRNA by Kaplan-Meier estimation. $\mathbf{d}$ Overall survival (OS) curve of CLL based on NDRG2 mRNA by Kaplan-Meier estimation 
Table 2 Associations between NDRG2 mRNA and baseline variables for the $102 \mathrm{CLL}$ subjects

\begin{tabular}{|c|c|c|}
\hline & Median $(95 \% \mathrm{Cl})$ & $P$-value \\
\hline \multicolumn{3}{|l|}{ Age (years) } \\
\hline$\leq 60$ years & $0.0015(0-0.0303)$ & 0.280 \\
\hline$>60$ years & $0.0017(0-0.0340)$ & \\
\hline \multicolumn{3}{|l|}{ Gender } \\
\hline Male & $0.0018(0-0.0366)$ & 0.194 \\
\hline Female & $0.0009(0-0.0193)$ & \\
\hline \multicolumn{3}{|l|}{ Binet stage } \\
\hline A & $0.0036(0.0004-0.0428)$ & 0.001 \\
\hline$B / C$ & $0.0011(0-0.0245)$ & \\
\hline \multicolumn{3}{|l|}{ Lymphocytes (×109/L) } \\
\hline$<50$ & $0.0018(0-0.0238)$ & 0.618 \\
\hline$\geq 50$ & $0.0013(0-0.0398)$ & \\
\hline \multicolumn{3}{|l|}{ LDH } \\
\hline$\leq \cup L N$ & $0.0025(0-0.0303)$ & 0.036 \\
\hline$>$ ULN & $0.0008(0-0.0375)$ & \\
\hline \multicolumn{3}{|l|}{$\beta_{2}-M G$} \\
\hline$\leq \cup L N$ & $0.0012(0-0.0341)$ & 0.539 \\
\hline$>$ ULN & $0.0018(0-0.0330)$ & \\
\hline \multicolumn{3}{|l|}{ CD38 $(n=100)$} \\
\hline$<30 \%$ & $0.0020(0-0.0358)$ & 0.063 \\
\hline$\geq 30 \%$ & $0.0008(0-0.0268)$ & \\
\hline \multicolumn{3}{|l|}{ ZAP-70 $(n=100)$} \\
\hline$<20 \%$ & $0.0017(0.0002-0.0389)$ & 0.244 \\
\hline$\geq 20 \%$ & $0.0020(0-0.0274)$ & \\
\hline \multicolumn{3}{|l|}{ IGHV $(n=101)$} \\
\hline Mutated & $0.0031(0.0002-0.0303)$ & 0.004 \\
\hline Unmutated & $0.0008(0-0.0371)$ & \\
\hline \multicolumn{3}{|l|}{ p53aberration } \\
\hline No TP53 mutation or p53 deletion & $0.0027(0.0001-0.0353)$ & $<0.001$ \\
\hline TP53 mutation or p53 deletion & $0.0003(0-0.0009)$ & \\
\hline
\end{tabular}

eliminate the predicted miR-28-5p and miR-650 binding sites (mean percent of luciferase activity reduction in the two miRNAs of $47 \%$ and $37 \%$, respectively, Fig. 2). The mutated luciferase reporter was unaffected by overexpression of miR-28-5p and miR-650. The results showed that miR-28-5p and miR-650 directly inhibited the expression of NDRG2 by binding to the target sequence.

\section{miR-28-5p and miR-650 expression in CLL patients}

qRT-PCR was performed in 30 CLL patients and $10 \mathrm{HC}$ to detect the expression of miR-28-5p and miR-650. We found that miR-28-5p and miR-650 were upregulated in CLL cells compared with normal lymphocytes. Of the 30 patients and $10 \mathrm{HC}$, the relative level of miR-28-5p
Table 3 Univariate and multivariate Cox regression analysis for time to treatment (TTT) and overall survival (OS) in 102 subjects with chronic lymphocytic leukemia

\begin{tabular}{|c|c|c|c|}
\hline \multirow[t]{2}{*}{ Variables } & \multirow{2}{*}{$\begin{array}{l}\text { Univariate analysis } \\
\text { (Kaplan-Meier) } \\
P \text {-value }\end{array}$} & \multicolumn{2}{|c|}{ Multivariate analysis } \\
\hline & & $\mathrm{HR}(95 \% \mathrm{Cl})$ & $P$-value \\
\hline \multicolumn{4}{|l|}{ गाT } \\
\hline Age $>60 y$ & 0.842 & $0.83(0.46-1.49)$ & 0.530 \\
\hline Sex (male) & 0.821 & $1.52(0.85-2.71)$ & 0.159 \\
\hline Binet B/C stage & $<0.001$ & $2.48(1.27-4.84)$ & 0.008 \\
\hline$A L C \geq 50 \times 10^{9} / \mathrm{L}$ & 0.977 & $0.90(0.50-1.63)$ & 0.721 \\
\hline $\mathrm{LDH}>U L N$ & 0.767 & $0.72(0.36-1.43)$ & 0.348 \\
\hline$\beta_{2}-M G>U L N$ & 0.095 & $1.49(0.81-2.74)$ & 0.204 \\
\hline CD38 ( $\geq 30 \%)$ & 0.164 & $1.01(0.55-1.84)$ & 0.988 \\
\hline ZAP-70 ( $\geq 20 \%)$ & 0.308 & $0.89(0.50-1.59)$ & 0.692 \\
\hline IGHV unmutated & $<0.001$ & $1.68(0.97-2.92)$ & 0.067 \\
\hline p53 aberration & $<0.001$ & $2.46(1.19-5.09)$ & 0.015 \\
\hline $\begin{array}{l}\text { NDRG2 expression } \\
\text { (high) }\end{array}$ & 0.001 & $2.01(1.11-3.64)$ & 0.022 \\
\hline \multicolumn{4}{|l|}{ OS } \\
\hline Age $>60 y$ & 0.700 & $0.89(0.34-2.35)$ & 0.814 \\
\hline Sex (male) & 0.633 & $1.33(0.51-3.48)$ & 0.563 \\
\hline Binet $B / C$ stage & 0.028 & $0.85(0.22-3.33)$ & 0.814 \\
\hline$A L C \geq 50 \times 10^{9} / L$ & 0.524 & $0.70(0.22-2.25)$ & 0.549 \\
\hline LDH $>$ ULN & 0.071 & $1.81(0.52-6.26)$ & 0.349 \\
\hline$\beta_{2}-M G>U L N$ & 0.813 & $1.29(0.46-3.59)$ & 0.628 \\
\hline CD38 ( $\geq 30 \%)$ & 0.002 & $2.01(0.79-5.13)$ & 0.143 \\
\hline ZAP-70 ( $\geq 20 \%)$ & 0.079 & $1.31(0.44-3.89)$ & 0.632 \\
\hline IGHV unmutated & $<0.001$ & $3.03(1.16-7.95)$ & 0.024 \\
\hline p53 aberration & $<0.001$ & $3.95(1.34-11.67)$ & 0.013 \\
\hline $\begin{array}{l}\text { NDRG2 expression } \\
\text { (high) }\end{array}$ & $<0.001$ & $3.43(1.06-11.14)$ & 0.040 \\
\hline
\end{tabular}

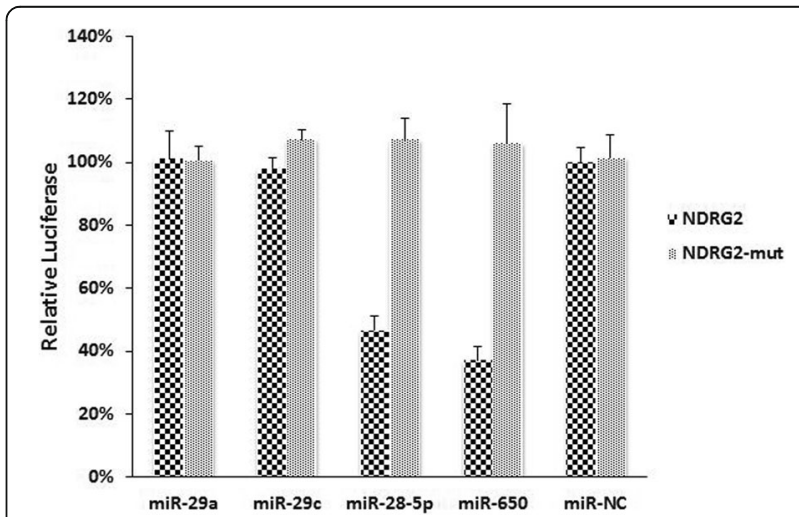

Fig. 2 Dual luciferase assay performed in HEK293T cells suggested that miR-28-5p and miR-650 mimics significantly suppress the activity of NDRG2 when compared to miR-NC 
expression was from 1.1408 to 22.9426 (median: 4.8444 ) and from 1.1684 to 3.0863 (median: 2.2215) and the relative expression level of miR-650 spanned from 0.0060 to 1.7415 (median: 0.0811 ) and from 0.0037 to 0.1023 (median: 0.0191), respectively. A statistical significance was found between the CLL patients and HC in miR-28-5p $(P<0.001)$ and miR-650 $(P=0.006)$ expression. Then we analyzed the correlations between expression levels of the two miRNAs and patients' clinical characteristics, including Binet stage, p53 aberrations, IGHV mutation status and ALC. A significant increase of miR-28-5p expression was observed in patients with Binet $\mathrm{B} / \mathrm{C}(P=0.044)$ and un-mutated IGHV $(P=0.011)$. Moreover, notable increase of miR-650 expression was observed in patients with Binet $\mathrm{B} / \mathrm{C}(P=0.013)$ and $\mathrm{p} 53$ aberrations $(P=0.037)$. NDRG2 mRNA was detected in the 30 CLL cases aforementioned. Interestingly, we found that the expression of NDRG2 was associated negatively with miR-28-5p $(r=-0.468$, $P=0.009$, Additional file 3$)$ and miR-650 $(r=-0.411$, $P=0.024$, Additional file 3 ).

\section{miR-28-5p and miR-650 inhibitors up-regulated NDRG2 expression and induced CLL cells apoptosis}

In order to identify the roles of miR-28-5p and miR-650 in regulating NDRG2 in primary CLL cells, we transiently transfected the primary cells from 11 newly diagnosed CLL cases were transiently transfected with miR-28-5p and miR-650 inhibitors and miR-NC, and detected the expression levels of miRNAs and NDRG2 expression $24 \mathrm{~h}$ after transfection. The results verified by qRT-PCR analysis of CLL cells treated with the two miRNAs inhibitors showed remarkable knocking down of miR-28-5p and miR-650 expression (Fig. 3a, c, $P=0.009$ and $P=0.019$, respectively) as well as upregulated NDRG2 at mRNA level after transfection of the two miRNAs inhibitors as compared with the cells transfected with miR-NC (Fig. 3b, d, $P=0.001$ and $P=0.031$, respectively). Western blot analysis showed that the median NDRG2 protein expression was 0.1252 (range, 0.0438-0.3383), 0.8341 (range, 0.3575-2.0262) and 0.7621 (range, 0.33481.6500) in CLL cells transfected with miR-NC, miR-28-5p inhibitors and miR-650 inhibitors, respectively. The results indicated that NDRG2 protein expression was markedly up-regulated after transfection with miR-28-5p inhibitors $(P<0.001)$ and miR-650 inhibitors $(P<0.001)$ compare with miR-NC (Fig. 4a, b). Moreover, up-regulated NDRG2 protein expression was observed in CLL cells from patients without p53 aberrations $(P<0.05)$ (Fig. 4c) and with harbored p53 aberrations $(P<0.05)$ (Fig. $4 d)$.

Apoptosis assay was performed to ascertain the biological effect of these miRNAs inhibitors on the apoptosis of primary CLL cells. Marked increase in apoptosis was observed the primary CLL cells transfected with miR-28-5p- and miR-650-inhibitors $(P=0.006$ and $P<0.001$, respectively (Fig. 5a), compared to miR-NC- transfected CLL cells. Significant increase in apoptosis was also found in transfection of the two miRNAs inhibitors into CLL cells from patients without p53 aberrations compared with miR-NC $(P=0.005$ and $P<0.001$, respectively, Fig. $5 \mathrm{~b}, \mathrm{~d})$. However, no increased apoptosis rates were found in CLL with p53 aberrations, after transfecting with the above miRNAs inhibitors $(P=0.305$ and $P=0.519$, respectively, Fig. $5 c$, e). These findings demonstrated that inhibition of miR-28-5p or miR-650 could induce more apoptosis in CLL cells in p53-dependent manner.

\section{Discussion}

NDRG2, located at chromosome $14 \mathrm{q} 11.2$, is an important member of the NDRG family and recognized as tumor suppressor. Series of studies have been done to explore the expression and the clinical significance of NDRG2 in cancers including hematological malignancies $[5,6,9]$. Nakahata $S$ et al. [6] found that NDRG2 expression was significantly reduced in adult T-cell leukemia lymphoma (ATLL) cell lines and primary acute-type ATLL samples, and downregulation of NDRG2 can activate the PI3K-AKT signaling pathway. Lchikawa $\mathrm{T}$ et al. [9] reported that loss of NDRG2 also enhanced activation of the NF-kB pathway in ATLL. In current work, we tentatively investigated the expression level of $N D R G 2$ and its relation with prognostic factors of CLL and found marked decrease of NDRG2 mRNA expression in CLL patients compared to HC. The observations showed that NDRG2 was significantly downregulated in CLL patients with Binet B/C, high $\mathrm{LDH}$ level, IGHV un-mutated and p53 aberrations. TP53 mutation and p53 deletion, which are the powerful prognostic factors in CLL, were defined as "p53 aberrations" in this study. The result revealed that patients with lower level of NDRG2 presented aggressive characteristics and NDRG2 may play a critical role in the pathogenesis and development of CLL. Importantly, we found a strong correlation between NDRG2 expression and TTT as well as OS. Patients with a lower expression level of NDRG2 had a significantly shorter TTT and inferior OS than those with a higher NDRG2 expression by univariate analysis. Multivariate analysis further demonstrated that NDRG2 mRNA was prognostic value for TTT and OS independent of IGHV mutation status as well as p53 abnormalities. These findings proved that NDRG2 expression should be a new prognostic factor for CLL. FISH analysis failed to detect del(11q22.3), del(13q14) and + 12 in part of CLL patients, for which those factors were not included in our survival analysis.

Based on the above results, we further investigated the molecular mechanisms underlying NDRG2 regulatory 

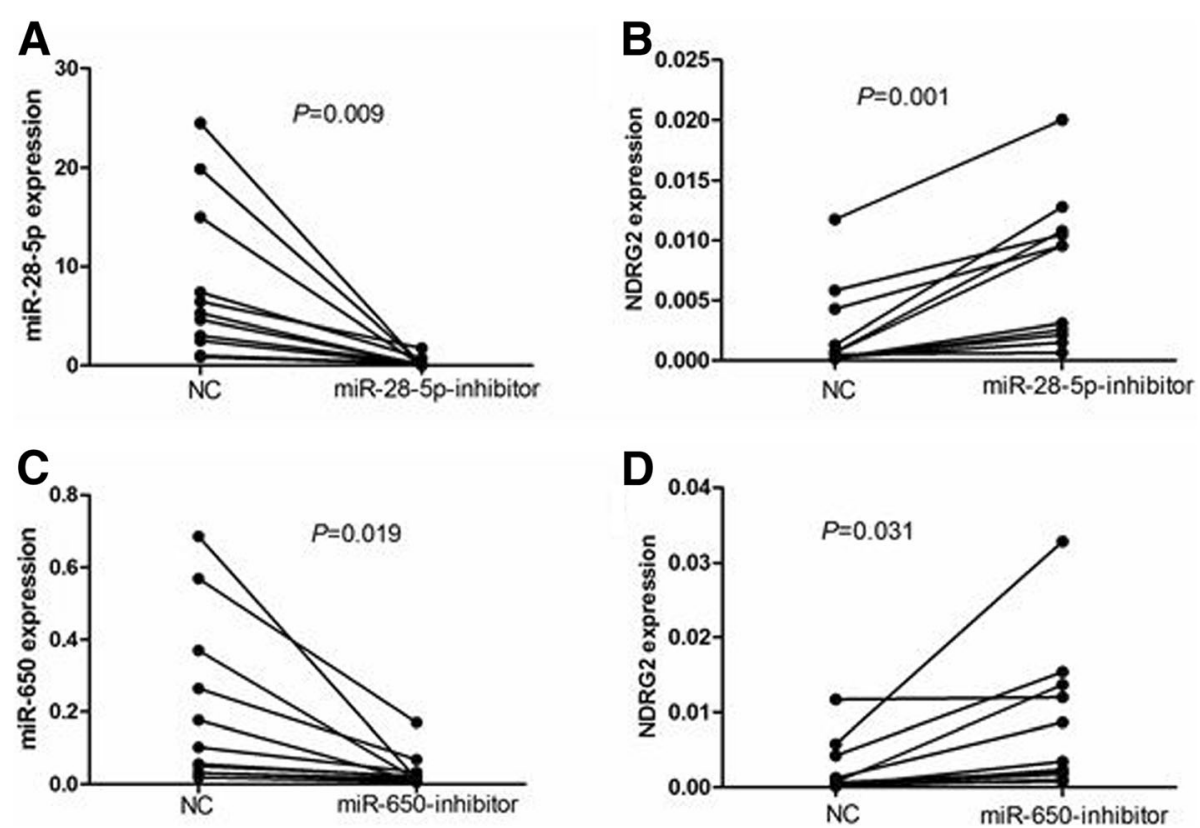

Fig. 3 The expression of NDRG2 and miRNAs before and after transfecting with miRNA inhibitors. The corresponding miRNAs fall significantly in groups treated with miR-28-5p and miR-650 inhibitors groups than treated with miR-NC $(P=0.009, \mathbf{a} ; P=0.019$, $\mathbf{c})$, separately. The primary CLL cells express obviously increased NDRG2 mRNA in miR-28-5p $(P=0.001)(\mathbf{b})$ and miR-650 $(P=0.031)(\mathbf{d})$ inhibitors groups
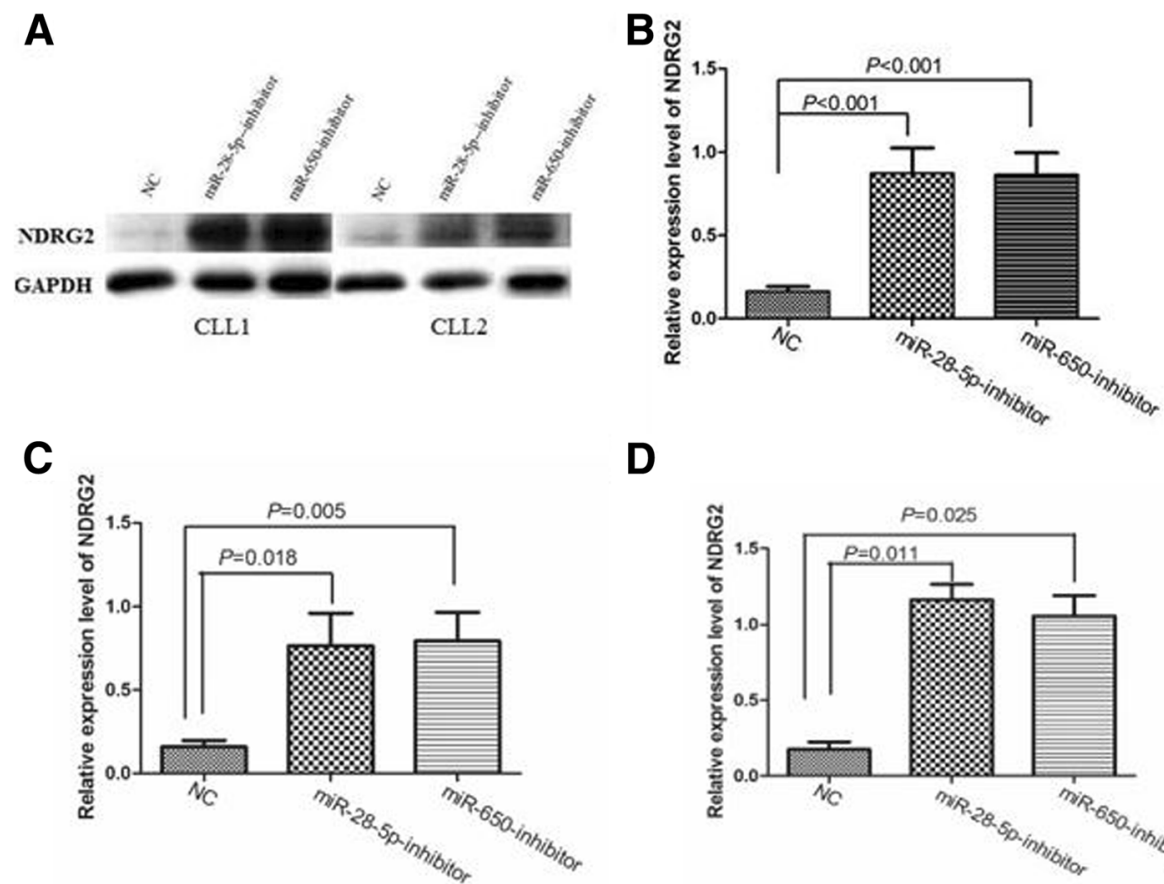

D

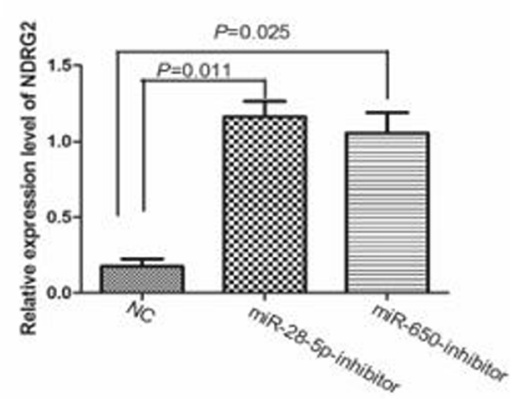

Fig. 4 a Up-regulate NDRG2 protein expression NDRG2 protein levels after transfection with miRNA inhibitors (including miR-28-5p, miR-650 and NC miRNA inhibitors) in 2 primary CLL cells (Western blot analysis) (CLL1: CLL cells from a patient with p53 deletion; CLL2: CLL cells from a patient without p53 aberrations); $\mathbf{b}$ In CLL primary cells, miR-28-5p and miR-650 inhibitors treated groups show significantly increased NDRG2 protein level compared to NC (median level, 0.8341 vs. 0.1252 , $P<0.001 ; 0.7621$ vs. $0.1252, P<0.001$ ). c Up-regulated NDRG2 protein expression in CLL cells from patients without p53 aberrations after transfection with miR-28-5p inhibitor $(P=0.018)$ and miR-650 inhibitor $(P=0.005)$. d Up-regulated NDRG2 protein expression in CLL cells from patients with p53 aberrations after transfection with miR-28-5p inhibitor $(P=0.011)$ and miR-650 inhibitor $(P=0.025)$ 


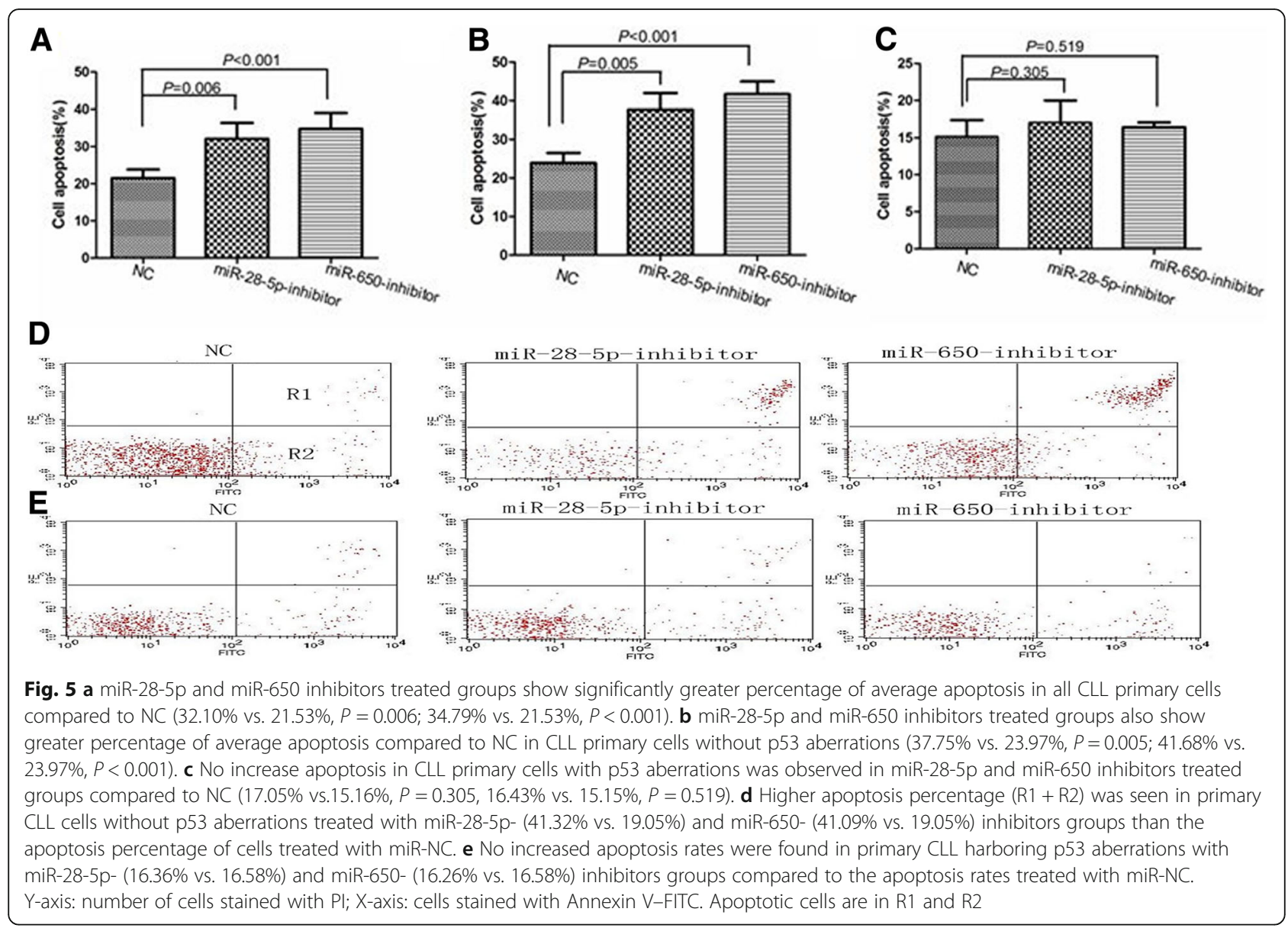

pathways. MiRNAs are a family of approximate 22 nucleotides small and single-stranded non-coding RNAs that negatively regulate gene expression $[12,13]$. In recent years, there is growing attention to the role of miRNAs in cancers, and abnormal miRNAs expression is extensively reported in hematologic neoplasms [14-17]. MiRNAs affect the stability of targeted oncogenes or tumor suppressors, thus leading to the impact on cellular physiology in certain malignancies. However, limited studies have ever examined miRNAs targeting NDRG2 in CLL. Therefore, we investigated miRNAs targeting NDRG2 and evaluate the effect on CLL cell apoptosis. Using computational analyses, four conserved miRNAs were identified as NDRG2-related miRNAs. The dual-luciferase assay confirmed that the mimics of miR-28-5p and miR-650 obviously suppressed the activity of $N D R G 2$. In order to understand whether the NDRG2 is a direct target of miR-28-5p and miR-650 in CLL, qRT-PCR was performed to determine the expression of NDRG2, miR-28-5p and miR-650 in 30 CLL patients and $10 \mathrm{HC}$. Interestingly, we found that the expression level of miR-28-5p and miR-650 were significantly increased in CLL patients compared to $\mathrm{HC}$, and were negatively associated with NDRG2. Furthermore, we examined the effects of antisense oligonucleotides targeting miR-28-5p and miR-650 on the primary CLL cells. We investigate transfection efficiency and found that the expression of miR-28-5p and miR-650 were significantly under-expressed after transfection with those miRNA inhibitors, yet the levels of NDRG2 mRNA and proteins were up-regulated in transfected cells with miR-28-5p and miR-650 inhibitors compared with the NC. This observation supplied strong evidence that NDRG2 expression can be regulated by miR-28-5p and miR-650 in CLL. In other words, miR-28-5p and miR-650 can function as oncogene negatively regulating the expression of tumor suppressor in CLL.

Previous studies indicated significantly increased miR-650 expression and its association with the progression in gastric cancer, colorectal cancer, hepatocellular cancer and glioma [10, 18-20]. Further, Feng et al. [10] described regulation of NDRG2 by miR-650 in human colorectal cancer cells, which is consistent with our findings. However, Mraz M et al. [21] found that CLL patients with higher expression of miR-650 had significantly longer OS and TTT as well as transfection with miR-650 resulted in a reduction in the proliferative capacity of B cells, which partly argued against our results. 
This disparity can be associated with the diverse biological characteristics of CLL in Chinese population from those of European origins. Almeida et al. [22] reported that miR-28-5p was downregulated in colorectal cancer cells compared with normal colon samples, and that overexpression of miR-28-5p reduced colorectal cancer cell proliferation, migration and invasion in vitro. This discrepancy from ours may be associated with miR-28-5p exerting different functions in diverse types of tumors. In addition, it is worth mentioning that the level of NDRG2 mRNA and protein were both up-regulated in transfected cells with miR-28-5p and miR-650 inhibitors, which is consistent with our previous work that demonstrated up-regulated levels of PTEN mRNA and proteins in transfected cells with miR-26a and miR-214 inhibitors as compared with the controls [23]. It is generally accepted that most animal miRNAs exert their regulatory effects through incomplete matching with 3'-untranslated region (3'-UTR) of their mRNA targets, repress target-gene expression at the level of translation, reducing the protein levels of their target genes, yet the mRNA levels of these genes are barely affected [24]. Nevertheless, some findings indicate that miRNAs share only partial complementarity with their targets, and can also induce mRNA degradation and reduce the mRNA levels of their target genes in mammals [25, 26], which may explain the results in current study.

We observed the knockdown of NDRG2 with miR-28-5p and miR-650 inhibitors inducing CLL cell apoptosis, yet found no increased apoptosis rates in patients with p53 aberrations following transfection with the above miRNAs inhibitors. Contrarily, significant apoptosis increase was seen in patients without p53 aberrations after transfection. Previous studies showed that overexpression of NDRG2 markedly promoted tumor cell apoptosis in renal cell carcinoma [27], esophageal carcinoma [28] and breast cancer [29]. Although we found the similar results, yet overexpression of NDRG2 promoting CLL cell apoptosis was only seen in patients without p53 aberrations. Liu et al. studied the association of NDRG2 with p53, and reported that NDRG2 was p53-inducible target gene that is transactivated by $\mathrm{p} 53$ and is required for the full p53-mediated apoptotic response [7]. Cao et al. also found that adenoviruses carrying NDRG2 enhanced p53-mediated apoptosis of hepatocarcinoma cells [30]. In our study, we found that NDRG2 expression was significantly reduced in CLL patients with p53 aberrations, yet increased by transfecting with related miRNAs-inhibitors promoting CLL cells apoptosis without p53 aberrations. However, association between NDRG2 and p53 pathway in CLL needs verification by expanding population samples due to limited cases included in current work.

\section{Conclusions}

This study for the first time has revealed that NDRG2 expression can be down-regulated in patients with CLL, and that NDRG2 mRNA levels may be a useful prognostic variable in CLL patients. Our results further indicate that downregulation of NDRG2 expression is related to the aberrant expression of miR-28-5p and miR-650, and the apoptosis-inducing effects of NDRG2 should involve p53 activation in patients with CLL. Potential therapeutic applications in CLL by restoring the NDRG2 activity via knockdown of miR-28-5p and/or miR-650 may be considerations together with the NDRG2/p53 feedback loop in future work.

\section{Additional files}

Additional file 1: Sequences of qRT-pCR primers of NDRG2 and miRNAs (PDF 140 kb)

Additional file 2: Predicting the possible binding sites of 4 miRNAs targeting NDRG2 by bioinformatics. (PDF $59 \mathrm{~kb}$ )

Additional file 3: NDRG2 mRNA levels indicating an inverse correlation with miR-28-5p and miR-650. (PDF $107 \mathrm{~kb}$ )

\section{Abbreviations}

ALC: Absolute lymphocyte count; ATLL: Adult T-cell leukemia lymphoma; CLL: Chronic lymphocytic leukemia; FISH: Fluorescence in situ hybridization; HC: Healthy controls; IWCLL: International workshop on chronic lymphocytic leukemia; LDH: Lactate dehydrogenase; miRNAs: microRNAs; NDRG2: NMYC downstream-regulated gene-2; OS: Overall survival; PI: Propidium iodide; TाT: Time to first treatment; $\beta 2-M G$ : $\beta 2$-microglobulin

\section{Funding}

This study was supported by National Natural Science Foundation of China (81370657, 81470328, 81600130, 81770166, 81720108002), Jiangsu Province's Medical Elite Programme (ZDRCA2016022), Project of National Key Clinical Specialty, National Science \& Technology Pillar Program (2014BAI09B12), Jiangsu Provincial Special Program of Medical Science (BL2014086 and BE2017751) and National Science and Technology Major Project (2017ZX09304032). The funders had no role in study design, data collection and analysis, decision to publish, or preparation of the manuscript.

\section{Availability of data and materials}

The dataset used and analyzed during this study is available from the corresponding author upon reasonable request.

\section{Authors' contributions}

YQY and TT analyzed the data and wrote the manuscript. WX and JYL designed the research and revised the manuscript critically for important content. LW, HYZ, WW, YX, JZW, YX and LF provided the clinical data. All authors read and approved the final manuscript.

\section{Ethics approval and consent to participate}

The ethics approval of this study was obtained from the Independent Ethics Committee of Nanjing Medical University. All subjects were given written informed consent complying the requirements of the Declaration of Helsinki. HEK293T cell line was purchased from ATCC, and did not require ethics approval for their use in this study.

Consent for publication

Not applicable.

Competing interests

The authors declare that they have no competing interests. 


\section{Publisher's Note}

Springer Nature remains neutral with regard to jurisdictional claims in published maps and institutional affiliations.

\section{Author details}

'Department of Hematology, the First Affiliated Hospital of Nanjing Medical University, Province Hospital, Nanjing 210029, Jiangsu, China. ${ }^{2}$ Key Laboratory of Hematology of Nanjing Medical University, Nanjing 210029, China. ${ }^{3}$ Collaborative Innovation Center for Cancer Personalized Medicine, Nanjing 210029, China

Received: 1 April 2018 Accepted: 8 October 2018

Published online: 22 October 2018

\section{References}

1. Lee DC, Kang YK, Kim WH, Jang YJ, Kim DJ, Park IY, et al. Functional and clinical evidence for NDRG2 as a candidate suppressor of liver cancer metastasis. Cancer Res. 2008;68:4210-20.

2. Hu XL, Liu XP, Lin SX, Deng YC, Liu N, Li X, et al. NDRG2 expression and mutation in human liver and pancreatic cancers. World J Gastroenterol. 2004;10:3518-21.

3. Li SJ, Wang WY, Li B, Chen B, Zhang B, Wang X, et al. Expression of NDRG2 in human lung cancer and its correlation with prognosis. Med Oncol. 2013;30:421.

4. Zhao H, Zhang J, Lu J, He X, Chen C, Li X, et al. Reduced expression of $\mathrm{N}$-Myc downstream-regulated gene 2 in human thyroid cancer. BMC Cancer. 2008;8:303.

5. Tschan MP, Shan D, Laedrach J, Eyholzer M, Leibundgut EO, Baerlocher GM, et al. NDRG1/2 expression is inhibited in primary acute myeloid leukemia. Leuk Res. 2010:34:393-8.

6. Nakahata S, Ichikawa T, Maneesaay P, Saito Y, Nagai K, Tamura T, et al. Loss of NDRG2 expression activates PI3K-AKT signalling via PTEN phosphorylation in ATLL and other cancers. Nat Commun. 2014;5:3393.

7. Liu N, Wang L, Li X, Yang Q, Liu X, Zhang J, et al. N-Myc downstreamregulated gene 2 is involved in p53-mediated apoptosis. Nucleic Acids Res. 2008:36:5335-49.

8. Wang J, Yin D, Xie C, Zheng $T$, Liang $Y$, Hong $X$, et al. The iron chelator Dp44mT inhibits hepatocellular carcinoma metastasis via N-Myc downstream-regulated gene 2 (NDRG2)/gp130/STAT3 pathway. Oncotarget. 2014:5:8478-91.

9. Ichikawa T, Nakahata S, Fujii M, Iha H, Morishita K. Loss of NDRG2 enhanced activation of the NF-KB pathway by PTEN and NIK phosphorylation for ATL and other cancer development. Sci Rep. 2015;5:12841.

10. Feng $L$, Xie $Y$, Zhang $H$, Wu Y. Down-regulation of NDRG2 gene expression in human colorectal cancer involves promoter methylation and microRNA650. Biochem Biophys Res Commun. 2011;406:534-8

11. Hallek M, Cheson BD, Catovsky D, Caligaris-Cappio F, Dighiero G, Döhner H, et al. International workshop on chronic lymphocytic leukemia. Guidelines for the diagnosis and treatment of chronic lymphocytic leukemia: a report from the international workshop on chronic lymphocytic leukemia updating the National Cancer Institute-working group 1996 guidelines. Blood. 2008:111:5446-56.

12. Reinhart BJ, Slack FJ, Basson M, Pasquinelli AE, Bettinger JC, Rougvie AE, et al. The 21-nucleotide let-7 RNA regulates developmental timing in Caenorhabditis elegans. Nature. 2000;403:901-6.

13. Pasquinelli AE, Reinhart BJ, Slack F, Martindale MQ, Kuroda MI, Maller B, et al. Conservation of the sequence and temporal expression of let-7 heterochronic regulatory RNA. Nature. 2000;408:86-9.

14. Borges NM, do Vale Elias M, Fook-Alves VL, Andrade TA, de Conti ML, Macedo MP, et al. Angiomirs expression profiling in diffuse large B-cell lymphoma. Oncotarget. 2016;7:4806-16.

15. de Leeuw DC, Verhagen HJ, Denkers F, Kavelaars FG, Valk PJ, Schuurhuis GJ, et al. MicroRNA-551b is highly expressed in hematopoietic stem cells and a biomarker for relapse and poor prognosis in acute myeloid leukemia. Leukemia. 2016;30:742-6.

16. Yamagishi M, Katano H, Hishima T, Shimoyama T, Ota Y, Nakano K, et al. Coordinated loss of microRNA group causes defenseless signaling in malignant lymphoma. Sci Rep. 2015;5:17868.

17. Yan W, Xu L, Sun Z, Lin Y, Zhang W, Chen J, et al. MicroRNA biomarker identification for pediatric acute myeloid leukemia based on a novel bioinformatics model. Oncotarget. 2015;6:26424-36.
18. Zhang X, Zhu W, Zhang J, Huo S, Zhou L, Gu Z, et al. MicroRNA-650 targets ING4 to promote gastric cancer tumorigenicity. Biochem Biophys Res Commun. 2010;395:275-80.

19. Zeng ZL, Li FJ, Gao F, Sun DS, Yao L. Upregulation of miR-650 is correlated with down-regulation of ING4 and progression of hepatocellular carcinoma. J Surg Oncol. 2013;107:105-10.

20. Sun B, Pu B, Chu D, Chu X, Li W, Wei D. MicroRNA-650 expression in glioma is associated with prognosis of patients. J Neuro-Oncol. 2013;115:375-80.

21. Mraz M, Dolezalova D, Plevova K, Stano Kozubik K, Mayerova V, Cerna K, et al. MicroRNA-650 expression is influenced by immunoglobulin gene rearrangement and affects the biology of chronic lymphocytic leukemia. Blood. 2012;119:2110-3.

22. Almeida Ml, Nicoloso MS, Zeng L, Ivan C, Spizzo R, Gafà R, et al. Strandspecific miR-28-5p and miR-28-3p have distinct effects in colorectal cancer cells. Gastroenterology. 2012;142:886-896.e9.

23. Zou ZJ, Fan L, Wang L, Xu J, Zhang R, Tian T, et al. miR-26a and miR-214 down-regulate expression of the PTEN gene in chronic lymphocytic leukemia, but not PTEN mutation or promoter methylation. Oncotarget. 2015;6:1276-85.

24. Pillai RS, Bhattacharyya SN, Artus CG, Zoller T, Cougot N, Basyuk E, et al. Inhibition of translational initiation by Let-7 MicroRNA in human cells. Science. 2005:309:1573-6.

25. Yekta S, Shih IH, Bartel DP. MicroRNA-directed cleavage of HOXB8 mRNA. Science. 2004;304:594-6.

26. Lim LP, Lau NC, Garrett-Engele P, Grimson A, Schelter JM, Castle J, et al. Microarray analysis shows that some microRNAs downregulate large numbers of target mRNAs. Nature. 2005;433:769-73.

27. Ma JJ, Liao CG, Jiang X, Zhao HD, Yao LB, Bao TY. NDRG2 suppresses the proliferation of clear cell renal cell carcinoma cell A-498. J Exp Clin Cancer Res. 2010;29:103.

28. Shi H, Li N, Li S, Chen C, Wang W, Xu C, et al. Expression of NDRG2 in esophageal squamous cell carcinoma. Cancer Sci. 2010;101:1292-9.

29. Kim HS, Kim MJ, Lim J, Yang Y, Lee MS, Lim JS. NDRG2 overexpression enhances glucose deprivation-mediated apoptosis in breast cancer cells via inhibition of the LKB1-AMPK pathway. Genes Cancer. 2014:5:175-85.

30. Cao W, Zhang JL, Feng DY, Liu XW, Li Y, Wang LF, et al. The effect of adenovirus-conjugated NDRG2 on p53-mediated apoptosis of hepatocarcinoma cells through attenuation of nucleotide excision repair capacity. Biomaterials. 2014;35:993-1003.
Ready to submit your research? Choose BMC and benefit from:
- fast, convenient online submission
- thorough peer review by experienced researchers in your field
- rapid publication on acceptance
- support for research data, including large and complex data types
- gold Open Access which fosters wider collaboration and increased citations
- maximum visibility for your research: over $100 \mathrm{M}$ website views per year
At BMC, research is always in progress. 